\title{
Update in Heart Rhythm Abnormalities and Indications for Pacemaker After Transcatheter Aortic Valve Implantation
}

Marina Saadi' ; Ana Paula Tagliari², MD; Luiz Cláudio Danzmann³ , MD; Eduardo Bartholomay³, MD; Adriano Nunes $\mathrm{Kochi}^{4}, \mathrm{MD}$; Eduardo Keller Saadi², MD, MSc, PhD

DOI: $10.21470 / 1678-9741-2017-0206$

\begin{abstract}
Objective: Rhythm abnormalities following transcatheter aortic valve implantation (TAVI) and indications for permanent pacemaker implantation (PPI) were reviewed, which aren't well established in the current guidelines. New left bundle branch block and atrioventricular block are the most common electrocardiographic changes after TAVI. PPI incidence ranges from $9-42 \%$ for selfexpandable and $\mathbf{2 . 5}-11.5 \%$ for balloon expandable devices. Not
\end{abstract}

only anatomical variations in conduction system have an important role in conduction disorders, but different valve characteristics and their relationship with cardiac structures as well. Previous right bundle branch block has been confirmed as one of the most significant predictors for PPI.

Keywords: Aortic Valve Stenosis. Transcatheter Aortic Valve Implantation. Arrhythmias, Cardiac. Pacemaker, Artificial.

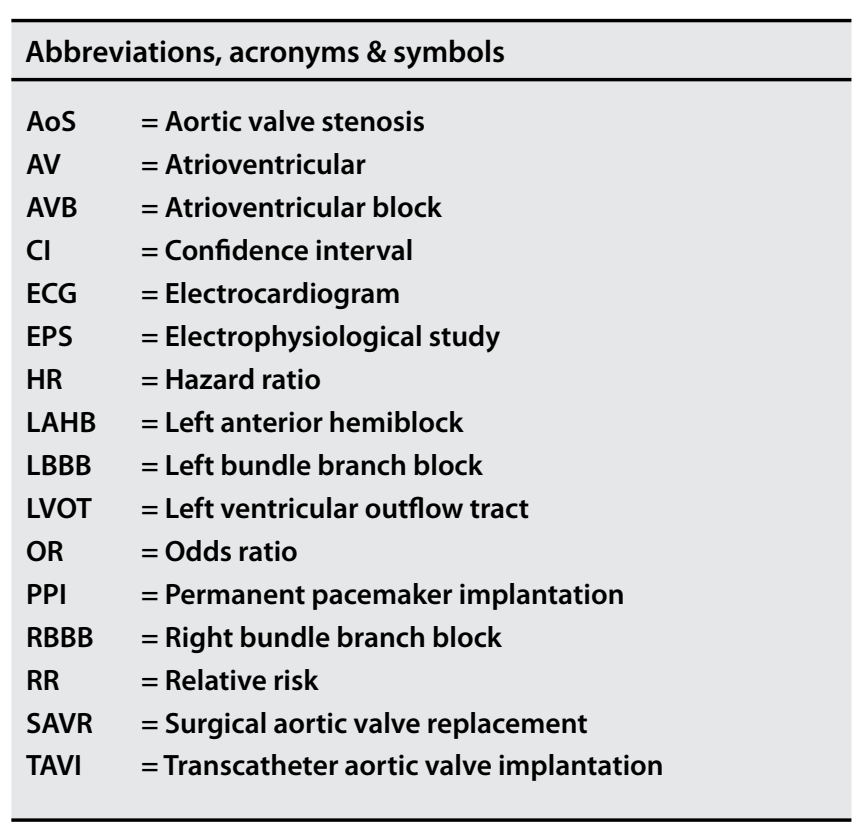

'Universidade Luterana do Brasil (ULBRA), Canoas, RS, Brazil.

${ }^{2}$ Department of Cardiovascular Surgery, Hospital de Clínicas de Porto Alegre (HCPA), Universidade Federal do Rio Grande do Sul (UFRGS), Porto Alegre, RS, Brazil. ${ }^{3}$ Department of Cardiology, Universidade Luterana do Brasil (ULBRA), Canoas, RS, Brazil. ${ }^{4}$ Department of Cardiology, Hospital de Clínicas de Porto Alegre (HCPA), Universidade Federal do Rio Grande do Sul (UFRGS), Porto Alegre, RS, Brazil.

This study was carried out at the Universidade Luterana do Brasil (ULBRA), Canoas, RS, Brazil and at the Hospital de Clínicas de Porto Alegre (HCPA), Universidade Federal do Rio Grande do Sul (UFRGS), Porto Alegre, RS, Brazil.

\section{INTRODUCTION}

Increased life expectancy has contributed to making cardiac valve diseases more frequent and relevant ${ }^{[1]}$.

Aortic valve stenosis (AoS), the most common cardiac valve disease, affects approximately 3\% of the population older than 75 years $^{[2]}$ and, usually, remains silent for many years.

However, once symptoms are present, survival decreases dramatically ${ }^{[3,4]}$, being surgical treatment the therapy of choice ${ }^{[5]}$.

Since the first clinical report in 2002, transcatheter aortic valve implantation (TAVI) has emerged as a valuable, less invasive and safe therapeutic alternative in patients with symptomatic severe AoS ${ }^{[6]}$.

Currently, TAVI is considered the gold standard for high-risk patients, the only option for inoperable ones, and, recently, noninferior to conventional surgery in intermediate risk patients ${ }^{[7-9]}$.

On the other hand, this is not a risk-free procedure, with atrioventricular (AV) conduction disturbances being a common complication ${ }^{[10]}$.

In this context, understanding post-procedural conduction disturbances' mechanisms and rates is an extremely current and relevant issue.

No financial support.

No conflict of interest.

Correspondence Address:

Ana Paula Tagliari

Rua Ramiro Barcelos, 2350 - Porto Alegre, RS, Brasil

Zip Code: 90035-903

E-mail: anapaulatagliari@yahoo.com.br or atagliari@hcpa.edu.br 
This study aims to review rhythm abnormalities after TAVI, besides the permanent pacemaker implantation (PPI) indications, which are not well established by the current guidelines.

\section{Rhythm Abnormalities}

Bradyarrhythmias are not uncommon after cardiac surgery, TAVI and heart transplantation. According to the 2013 European Society of Cardiology guidelines on cardiac pacing and cardiac resynchronization therapy ${ }^{[11]}$, complete atrioventricular block (AVB) may occur in $1-4 \%$ of cardiac surgeries, $8 \%$ of repeat valve surgeries and up to $20-24 \%$ of interventions for calcified AoS or tricuspid valve replacement.

Following TAVI, new left bundle branch block (LBBB) and AVB are the main electrocardiographic changes and the consequent need for a permanent pacemaker is the most expensive shortterm adverse event ${ }^{[12]}$.

The incidence of post-procedural conduction disturbances varies among studies, being 20\% in complete AVB, $7 \%$ to $83 \%$ in $\mathrm{LBBB}, 2 \%$ in right bundle branch block (RBBB) and $2 \%$ in left anterior hemiblock (LAHB) ${ }^{[13-16]}$.

By Urena et al. ${ }^{[13]}, 37.7 \%$ of these new LBBB are resolved before hospital discharge and 57\% in 6-12-month follow-up period.

The PARTNER trial analysis showed that, although new LBBB has not been associated with increased 1-year mortality, it was associated with a higher in-hospital pacemaker indication [8.3\% versus $2.8 \% ; P=0.005]$ and from discharge to one year $(4.7 \%$ vs. $1.5 \% ; P=0.01)$, as well as failure to improve left ventricular ejection fraction (52.8 vs. 58.1\%; $P<0.001)^{[17]}$.

In contrast, another study showed new LBBB as an independent predictor of all-cause mortality [hazard ratio (HR) 1.54; 95\% confidence interval (CI) $1.12-2.10$ ]. Cardiovascular mortality rate was $9.4 \%$ for patients without TAVI-induced LBBB and 18\% for new LBBB ${ }^{[15]}$.

Similarly, for Makki et al. ${ }^{[18]}$, PPI has been associated with increased short- and long-term mortality, which may represent inherent conduction abnormality or pacemaker operation morbidity.

\section{PPI Indications}

Pacemaker implantation after TAVI has had the same recommendations as non-surgical patients with persistent bradycardia, such as symptomatic bradycardia, complete AVB, type II second-degree AVB, new LBBB in combination with infrahisian conduction delay (HV interval $\geq 70 \mathrm{~ms}$ or second or thirddegree Hiss-Purkinje block) ${ }^{[11]}$.

The 2013 European Society of Cardiology guideline considers indication class I, level C "high degree or complete AVB after cardiac surgery and TAVI, with a period of clinical observation up to 7 days (Table 1). In case of complete AVB with a low rate of escape rhythm, this observation period can be shortened since the resolution is unlikely"[1]].
In the post-TAVI phase, the management depends on the prosthesis implanted. For instance, early removal of the temporary pacing lead seems to be safe after the balloon expandable Edwards Sapien ${ }^{\circledR}$ prosthesis, in the absence of intraprocedural advanced degree blocks. Then, a 24-48 hour electrocardiographic monitoring followed by a daily 12-leads electrocardiogram (ECG) until the discharge is recommended. On the contrary, when a self-expandable CoreValve ${ }^{\circledR}$ prosthesis is chosen, a 48-72 hour monitoring before removal of the temporary pacing lead might be recommended even when the ECG early after TAVI is normal[ ${ }^{[19]}$.

QRS duration is another factor that may assist the decision about early or late pacing lead removal. According to a Takahashi's et al. ${ }^{[20]}$ study, in which patients with QRS duration $<120$ ms were submitted to early pacing lead removal and those with QRS $\geq 120$ ms to late removal, no PPI was indicated in the first group, while $39 \%$ of the latter developed a delayed AVB $(P=0.0001)$.

Taking into account that TAVI is routinely performed under heparin anticoagulation, which potentially may lead to an increased bleeding rate for PPI immediately after TAVI, Schwerg et al. [.21] evaluated patients who have undergone PPI implantation on the same day of TAVI implant (group A) and patients in whom the PPI was performed at least 1 day after TAVI (group B) (3.8 44.5 days). In this study, procedure times, fluid loss via drainage systems, and drainage times were neither significantly different between the groups nor when compared to a historical group.

\section{PPI Risk Factors}

Many factors have been identified for PPI requirement after TAVI, mainly related to baseline conductions defects, device selection and anatomical characteristics ${ }^{[2]}$. Thus, a careful preTAVI screening is overwhelming important ${ }^{[19]}$.

Advanced age, permanent atrial fibrillation, use of digoxin, larger or oversized prosthesis ${ }^{[23,24]}$, for example, are considered clinical predictors for new LBBB post-TAVI, while left heart axis, lower mean heart rate, and prolonged PQ and QRS times are considered electrocardiographic parameters for severe cardiac conduction defects requiring PPI in patients with new $\mathrm{LBBB}^{[24]}$.

During the procedure predilatation and valve deployment are the most critical steps for conduction disorders development ${ }^{[25,26]}$.

Regarding the available devices, the differences in shape, height of the frame, depth of implantation and different physical properties account for the different PPI incidences observed ${ }^{[19]}$.

A meta-analysis published in 2014 with 41 studies comprising 11210 post-TAVI patients, showed an unadjusted 2.5-fold higher risk for CoreValve ${ }^{\circledast}(28 \%)$ compared to Sapien ${ }^{\circledast}(6 \%)$. The risk was increased for men [relative risk (RR) 1.23; $P<0.01$ ]; previous firstdegree AVB (RR 1.52; $P<0.01)$, LAHB (RR 1.62; $P<0.01)$ or RBBB (RR 2.89; $P<0.01)$ and intraprocedural AVB (RR 3.49; $P<0.01)^{[27]}$.

Table 1. Recommendation for pacing after transcatheter aortic valve implantation ${ }^{[11]}$.

\begin{tabular}{l|c|c}
\hline Recommendation & Class of recommendation & Level \\
\hline I) High degree or complete AV block after TAVI & I & C \\
\hline
\end{tabular}


In a more recent study, the combination of pre-TAVI prolonged PR interval (>220 ms) and increased QRS duration (>120 ms) reached a positive predictive value for PPI of $80 \%$, suggesting to use such parameters as periprocedural PPI markers ${ }^{[28]}$.

Analyzing national data, the Brazilian Registry of 418 patients with severe AoS who had undergone TAVI demonstrated a 30-day PPI incidence of $25.2 \%$. On multivariable analysis only CoreValve $^{\circledR}$ vs. Sapien $X T^{\oplus}$ [odds ratio (OR) 4.24, 95\% Cl 1.56 - 11.49; $P=0.005$ ], baseline RBBB (OR 4.41, 95\% Cl 2.20 - 8.82; $P<0.001)$, and balloon pre-dilatation (OR 1.75, 95\% Cl $1.02-3.02$; $P=0.04$ ) were independent PPI predictors ${ }^{[29]}$.

Supporting these data, solely baseline RBBB and deep valve implantation were found as predictors of high-degree AVB and PPI requirement in a separate multivariable analysis of a study published in 2011 in the American Journal of Cardiology ${ }^{[30]}$.

In terms of potential tools for AVB risk stratification in the electrophysiological study (EPS), a cohort led by Kostoupoulou et al..16] analyzed 30 patients who underwent EPS, 25 of these had a second EPS after 48h. Delta-HV did not show to be a risk factor and baseline HV interval did only in univariate analysis.

Opposing these findings, physicians from the Montreal Heart Institute followed 75 patients who had undergone EPS before and after TAVI. In multivariate analysis, the delta-HV interval was independently associated with AVB development and its sensitivity and specificity for predicting AVB were, respectively, $100 \%$ and $84.4 \%$ for a delta-HV interval $\geq 13 \mathrm{~ms}^{[31]}$.

Considering the left ventricular outflow tract (LVOT) in terms of amount of calcium, perimeter and device size relative to LVOT, as well as the degree of valve protrusion into the LVOT, once these factors could affect the underlying conduction system, Rodríguez-Olivares et al. ${ }^{[32]}$ performed a study where computed tomography was used to assess LVOT. By multivariate analysis RBBB at baseline (OR 2.9, 95\% Cl $1.2-6.9$; $P=0.014)$, next generation valves (OR 2.1,95\% IC 1.0-4.5; $P=0.048$ ), depth of implantation (OR 1.2 per $1 \mathrm{~mm}$ increment, 95\% IC 1.1-1.3; $P<0.001)$ and LVOT sizing (OR per 1\% increment 1.0, 95\% IC 1.0$1.06 ; P=0.022$ ) were predictors of PPI.

\section{Heart Block Mechanisms after TAVI}

By Young Lee et al. ${ }^{[10]}$ inter-individual variation in the penetrating bundle length and depth of septal penetration and variation in the location of the proximal portion of left bundle determine how susceptible these structures are to injury during TAVI.

While conduction abnormalities in surgical aortic valve replacement (SARV) are attributed to the surgical method suturing along the sewing ring near the membranous septum, removal of the native aortic valve and edema - the susceptibility to AVB in TAVI is more specific.

In CoreValve ${ }^{\circledast}$, the AVB risk is partly due to the valve design and the potential for a deeper valve implantation into the LVOT $^{[10]}$.

Kammler et al. ${ }^{[33]}$ identified that the mean distance from the annular margin of the non-coronary cusp to the ventricular end of the prosthesis was significantly longer in patients with pacemaker requirement $(9.7 \pm 4.1 \mathrm{~mm}$ vs. $6.3 \pm 3.4 \mathrm{~mm} ; P=0.0017)$.
A cut-off value of $6 \mathrm{~mm}$ predicted this need with a sensitivity of $89 \%$ and specificity of $40 \%$.

Nuis et al. ${ }^{[25]}$ also reported a direct relationship between the balloon/annulus ratio during balloon valvuloplasty and the development of new conduction disturbance, with a balloon/ annulus ratio close to 1.0 as an acceptable compromise to avoid it.

\section{PPI Rates}

PPI after TAVI incidence has been reported ranging from 9\% to $42 \%$ for self-expandable valves (CoreValve ${ }^{\circledR}$ ) and from $2.5 \%$ to $11.5 \%$ for balloon expandable valves (Edwards Sapien $\left.{ }^{\circledR}\right)^{[34]}$.

In the Partner 2 trial, where the Sapien $X \mathrm{~T}^{\circledR}$ system was used in patients with severe AoS and intermediate surgical risk, the 30-day PPI rate was $8.5 \%{ }^{[7]}$.

Comparing two generations of self-expanding repositionable valves, the PPI rates were $25.5 \%$ for CoreValve ${ }^{\circledR}$ and $26.7 \%$ for the new generation Evolut $\mathrm{R}^{\circledR[8]}$.

In the CHOICE trial, a lower 30-day pos-procedural PPI need was observed in the balloon-expandable group (Sapien $X \mathrm{X}^{\circledR}$ ) when compared to the self-expandable group (Corevalve ${ }^{\circledR}$ ) (17.3\% vs. 37.6\%, RR 0.46, 95\% Cl 0.28 - 0.74). Besides, cardiovascular mortality within 30 days was $4.1 \%$ in the first and $4.3 \%$ in the second group (RR 0.97, 95\% Cl 0.29 - 3.25; $P=0.99)^{[35]}$.

Another study comparing second generation devices Direct Flow Medical ${ }^{\circledR}$, Lotus ${ }^{\circledR}$, Evolut $\mathrm{R}^{\circledR}$ or Sapien $3{ }^{\circledR}(2 \mathrm{G})$ to first generation - Sapien $X T^{\circledR}$, CoreValve ${ }^{\circledR}(1 \mathrm{G})$, showed no differences regarding $P P I$ requirement (6.5\% vs. 7.8\%; $P=0.46$ ); but patients treated with $1 \mathrm{G}$ devices suffered more 30-day adverse events (free of adverse events $75.3 \%$ vs. 88.8\%, HR 2.4; 95\% Cl $1.4-4.0$; $P=0.01)^{[36]}$

According to access routes, The German aortic valve registry (GARY), the biggest registry about TAVI, showed that 1-year pacemaker need was $26.2 \%$ in transvascular approach and $14.1 \%$ in transapical ${ }^{[37]}$.

Finally, in a meta-analysis published in 2016, which compared TAVI with conventional SVAR in low and intermediate risk patients, a higher PPI rate after TAVI was observed when compared to SAVR $(21.6 \% \text { vs. } 7.5 \% \text {, OR } 7.4,95 \% \mathrm{Cl} 1.98-8.34 ; P<0.001)^{[38]}$. The same finding has not been seen with sutureless devices, which have a PPI incidence similar to TAVI (5-17\%) ${ }^{[39-42]}$.

\section{CONCLUSION}

Not only anatomical variations in each patient conduction system may have an important role in the conduction disorders prevalence after TAVI, as well as the different valve implanted and its characteristics in terms of diameter and relationship with other cardiac structures. Self-expandable devices are related to a higher incidence of PPI need than balloon-expandable valves.

Some baseline features, like RBBB, have been confirmed as significant predictors of PPI need. Moreover, new LBBB, which most often occur in the first 48 hours after TAVI, may also be a PPI risk factor.

Further studies may be necessary for better understanding of rhythm abnormalities and to establish the permanent pacemaker implantation criteria after TAVI. 


\section{Authors' roles \& responsibilities}

MS

Substantial contributions to the conception or design of the work; or the acquisition, analysis, or interpretation of data for the work; drafting the work or revising it critically for important intellectual content; final approval of the version to be published

APT Substantial contributions to the conception or design of the work; or the acquisition, analysis, or interpretation of data for the work; drafting the work or revising it critically for important intellectual content; final approval of the version to be published

LCD Substantial contributions to the conception or design of the work; or the acquisition, analysis, or interpretation of data for the work; drafting the work or revising it critically for important intellectual content; final approval of the version to be published

EB Substantial contributions to the conception or design of the work; or the acquisition, analysis, or interpretation of data for the work; drafting the work or revising it critically for important intellectual content; final approval of the version to be published

ANK Substantial contributions to the conception or design of the work; or the acquisition, analysis, or interpretation of data for the work; drafting the work or revising it critically for important intellectual content; final approval of the version to be published

Substantial contributions to the conception or design of the work; or the acquisition, analysis, or interpretation of data for the work; drafting the work or revising it critically for important intellectual content; final approval of the version to be published

\section{REFERENCES}

1. Nkomo VT, Gardin JM, Skelton TN, Gottdiener JS, Scott CG, EnriquezSarano M. Burden of valvular heart diseases: a population-based study. Lancet. 2006;368(9540):1005-11.

2. Horstkotte D, Loogen F. The natural history of aortic valve stenosis. Eur Heart J. 1988;9(Suppl E):57-64.

3. Frank S, Johnson A, Ross J Jr. Natural history of valvular aortic stenosis. Br Heart J. 1973:35(1):41-6.

4. Braunwald E, Zipes DP, Libby P. Braunwald's heart disease: a textbook of cardiovascular medicine. 9th ed. São Paulo: Roca; 2003.

5. Sorgato A, Faggiano P, Aurigemma GP, Rusconi C, Gaasch WH. Ventricular arrhythmias in adult aortic stenosis: prevalence, mechanisms, and clinical relevance. Chest. 1998;113(2):482-91.

6. Cribier A, Eltchaninoff H, Bash A, Borenstein N, Tron C, Bauer F, et al. Percutaneous transcatheter implantation of an aortic valve prosthesis for calcific aortic stenosis: first human case description. Circulation. 2002;106(24):3006-8.

7. Leon MB, Smith CR, Mack MJ, Makkar RR, Mumtaz M, Adams DH, et al. Transcatheter or surgical aortic-valve replacement in intermediate-risk patients. N Engl J Med. 2017;376(14):1321-31.

8. Reardon MJ, Van Mieghem NM, Popma JJ, Kleiman NS, Søndergaard L, Mumtaz M, et al; SURTAVI Investigators. Surgical or transcatheter aortic-valve replacement in intermediate-risk patients. N Engl J Med. 2017;376(14):1321-31.

9. Søndergaard L, Steinbrüchel DA, Ihlemann N, Nissen H, Kjeldsen BJ,
Petursson P, et al. Two-year outcomes in patients with severe aortic valve stenosis randomized to transcatheter versus surgical aortic valve replacement: The All-Comers Nordic Aortic Valve Intervention Randomized Clinical Trial. Circ Cardiovasc Interv. 2016;9(6). pii: e003665.

10. Young Lee M, Chilakamarri Yeshwant S, Chava S, Lawrence Lustgarten D. Mechanisms of heart block after transcatheter aortic valve replacement - cardiac anatomy, clinical predictors and mechanical factors that contribute to permanent pacemaker implantation. Arrhythm Electrophysiol Rev. 2015;4(2):81-5.

11. European Society of Cardiology (ESC)1; European Heart Rhythm Association (EHRA), Brignole M, Auricchio A, Baron-Esquivias G, Bordachar P, Boriani G, Breithardt OA, et al. 2013 ESC guidelines on cardiac pacing and cardiac resynchronization therapy: the task force on cardiac pacing and resynchronization therapy of the European Society of Cardiology (ESC). Developed in collaboration with the European Heart Rhythm Association (EHRA). Europace. 2013;15(8):1070-118.

12. Orlando R, Pennant M, Rooney S, Khogali S, Bayliss S, Hassan A, et al. Cost-effectiveness of transcatheter aortic valve implantation (TAVI) for aortic stenosis in patients who are high risk or contraindicated for surgery: a model-based economic evaluation. Health Technol Assess. 2013;17(33):1-86.

13. Urena M, Mok M, Serra V, Dumont E, Nombela-Franco L, DeLarochellière $\mathrm{R}$, et al. Predictive factors and long-term clinical consequences of persistent left bundle branch block following transcatheter aortic valve implantation with a balloon-expandable valve. J Am Coll Cardiol. 2012;60(18):1743-52.

14. Testa L, Latib A, De Marco F, De Carlo M, Agnifili M, Latini RA, et al. Clinical impact of persistent left bundle-branch block after transcatheter aortic valve implantation with CoreValve Revalving System. Circulation. 2013;127(12):1300-7.

15. Houthuizen P, Van Garsse LA, Poels TT, de Jaegere P, van der Boon RM, Swinkels BM, et al. Left bundle-branch block induced by transcatheter aortic valve implantation increases risk of death. Circulation. 2012;126(6):720-8.

16. Kostopoulou A, Karyofillis P, Livanis E, Thomopoulou S, Stefopoulos C, Doudoumis K, et al. Permanent pacing after transcatheter aortic valve implantation of a CoreValve prosthesis as determined by electrocardiographic and electrophysiological predictors : a singlecenter experience. Europace. 2016;18(1):131-7.

17. NazifTM, Williams MR, Hahn RT, Kapadia S, Babaliaros V, Rodés-Cabau $\mathrm{J}$, et al. Clinical implications of new-onset left bundle branch block after transcatheter aortic valve replacement : analysis of the PARTNER experience. Eur Heart J. 2014;35(24):1599-607.

18. Makki N, Dollery J, Jones D, Crestanello J, Lilly S. Conduction disturbance after TAVR: Electrophysiological studies and pacemaker dependency. Cardiovasc Revasc Med. 2017;18(5S1):S10-S13.

19. Fraccaro C, Napodano M, Tarantini G. Conduction disorders in the setting of transcatheter aortic valve implantation: a clinical perspective. Catheter Cardiovasc Interv. 2013;81 (7):1217-23.

20. Takahashi M, Mouillet G, Deballon R, Sudre A, Lellouche N, Lim P, et al. Impact of QRS duration on decision of early removal of pacing catheter after transcatheter aortic valve replacement with Corevalve device. Am J Cardiol. 2017;120(5):838-43.

21. Schwerg M, Baldenhofer G, Dreger H, Bondke H, Stangl K, Laule M, et al. Complete atrioventricular block after TAVI: when is pacemaker implantation safe? Pacing Clin Electrophysiol. 2013;36(7):898-903.

22. McDonnell KM, Shepard RK. Conduction disorders after transcatheter aortic valve implantation: a focused review. Curr Treat Options Cardiovasc Med. 2013;15(4):488-96.

23. Schroeter T, Linke A, Haensig M, Merk DR, Borger MA, Mohr FW, et al. Predictors of permanent pacemaker implantation after Medtronic CoreValve bioprosthesis implantation. Europace. 2012;14(12):1759-63.

24. Nijenhuis VJ, Van Dijk VF, Chaldoupi SM, Balt JC, Ten Berg JM. Severe 
conduction defects requiring permanent pacemaker implantation in patients with a new-onset left bundle branch block after transcatheter aortic valve implantation. Europace 2017;19(6):1015-21.

25. Nuis R, Van Mieghem NM, Schultz CJ, Tzikas A, Van der Boon RM, Maugenest AM, et al. Timing and potential mechanisms of new conduction abnormalities during the implantation of the Medtronic CoreValve System in patients with aortic stenosis. Eur Heart J. 2011;32(16):2067-74

26. Roten L, Stortecky S, Scarcia F, Kadner A, Tanner H, Delacrétaz E, et al. Atrioventricular conduction after transcatheter aortic valve implantation and surgical aortic valve replacement. J Cardiovasc Electrophysiol. 2012;23(10):1115-22.

27. Siontis GC, Jüni P, Pilgrim T, Stortecky S, Büllesfeld L, Meier B, et al. Predictors of permanent pacemaker implantation in patients with severe aortic stenosis undergoing TAVR: a meta-analysis. J Am Coll Cardiol. 2014;64(2):129-40.

28. Becker M, Blangy H, Folliguet T, Villemin T, Freysz L, Luc A, et al. Incidence, indications and predicting factors of permanent pacemaker implantation after transcatheter aortic valve implantation: a retrospective study. Arch Cardiovasc Dis. 2017;110(10):508-16.

29. Gensas CS, Caixeta A, Siqueira D, Carvalho LA, Sarmento-Leite R, Mangione JA, et al; Brazilian Registry in Transcatheter Aortic Valve Implantation Investigators. Predictors of permanent pacemaker requirement after transcatheter aortic valve implantation: insights from a Brazilian registry. Int J Cardiol. 2014;175(2):248-52.

30. Guetta V, Goldenberg G, Segev A, Dvir D, Kornowski R, Finckelstein A, et al. Predictors and course of high-degree atrioventricular block after transcatheter aortic valve implantation using the CoreValve Revalving System. Am J Cardiol. 2011;108(11):1600-5.

31. Rivard L, Schram G, Asgar A, Khairy P, Andrade JG, Bonan R, et al. Electrocardiographic and electrophysiological predictors of atrioventricular block after transcatheter aortic valve replacement. Heart Rhythm. 2015;12(2):321-9.

32. Rodríguez-Olivares R, van Gils L, El Faquir N, Rahhab Z, Di Martino LF, van Weenen $\mathrm{S}$, et al. Importance of the left ventricular outflow tract in the need for pacemaker implantation after transcatheter aortic valve replacement. Int J Cardiol. 2016;216:9-15

33. Kammler J, Blessberger H, Fellner F, Kypta A, Lambert T, Engl M, et al.
Implantation depth measured by 64-slice computed tomography is associated with permanent pacemaker requirement following transcatheter aortic valve implantation with the Core Valve ${ }^{\circledast}$ system. J Cardiol. 2016;67(6):513-8.

34. Bagur R, Rodés-Cabau J, Gurvitch R, Dumont É, Velianou JL, Manazzoni J, et al. Need for permanent pacemaker as a complication of transcatheter aortic valve implantation and surgical aortic valve replacement in elderly patients with severe aortic stenosis and similar baseline electrocardiographic findings. JACC Cardiovasc Interv. 2012;5(5):540-51.

35. Abdel-Wahab M, Mehilli J, Frerker C, Neumann FJ, Kurz T, Tölg R, et al; CHOICE investigators. Comparison of balloon-expandable vs self-expandable valves in patients undergoing transcatheter aortic valve replacement: the CHOICE randomized clinical trial. Jama. 2014;311(15):1503-14.

36. Ruparelia N, Latib A, Kawamoto H, Buzzatti N, Giannini F, Figini F, et al. A Comparison between first-generation and second-generation transcatheter aortic valve implantation (TAVI) devices: a propensitymatched single-center experience. J Invasive Cardiol. 2016;28(5):210--6.

37. Mohr FW, Holzhey D, Möllmann H, Beckmann A, Veit C, Figulla HR, et al. The German Aortic Valve Registry: 1-year results from 13,680 patients with aortic valve disease. Eur J Cardiothorac Surg. 2014;46(5):808-6.

38. Kondur A, Briasoulis A, Palla M, Penumetcha A, Mallikethi-Reddy S, Badheka A, et al. Meta-analysis of transcatheter aortic valve replacement versus surgical aortic valve replacement in patients with severe aortic valve stenosis. Am J Cardiol. 2016;117(2):252-7.

39. Tagliari AP, Moura L, Dussin LH, Saadi EK. Sutureless aortic prosthesis implantation: the first Brazilian experience with Perceval device. Brazilian J Cardiovasc Surg. 2016;31(4):334-6.

40. Mazine A, Teoh K, Bouhout I, Bhatnagar G, Pelletier M, Voisine P, et al. Sutureless aortic valve replacement: a Canadian multicentre study. Can J Cardiol. 2015;31(1):63-8.

41. Shrestha M, Fischlein T, Meuris B, Flameng W, Carrel T, Madonna F, et al. European multicentre experience with the sutureless Perceval valve: clinical and haemodynamic outcomes up to 5 years. Eur J Cardiothorac Surg. 2016:49(1):234-41.

42. Zannis K, Joffre J, Czitrom D, Folliguet T, Noghin M, Lansac MN, et al. Aortic valve replacement with the perceval $S$ bioprosthesis: singlecenter experience in 143 patients. J Heart Valve Dis. 2014;23(6):795-802. 